\title{
5
}

\section{Electricity Cogeneration using an Open Gas Turbine}

\author{
Anita Kovac Kralj \\ University of Maribor (Faculty of Chemistry and Chemical engineering) \\ Slovenia
}

\section{Introduction}

A gas turbine is a rotary engine that extracts energy from a flow of combustion gas. Gas turbines operate on the principle that fuel and air will burn in a combustion chamber. The outlet gas serves as a working fluid (Fig.1).

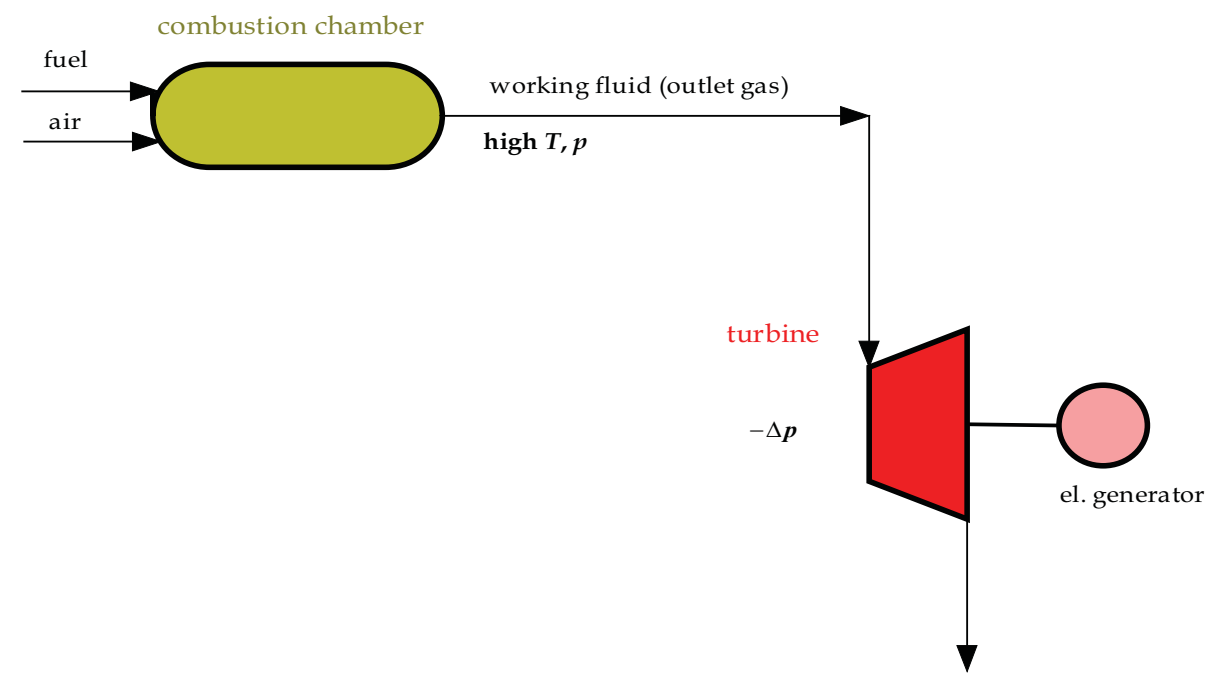

Fig. 1. Gas turbine

\section{Important}

Our main purpose is to use existing gases during chemical processes, in order to drive a turbine. Processes, which operate under high pressures, followed the cleaning at low pressures, can be exploited for electricity cogeneration. The high operating pressure at a reactor's outlet can be exploited to produce electricity using the open gas turbine system (Fig. 2). 


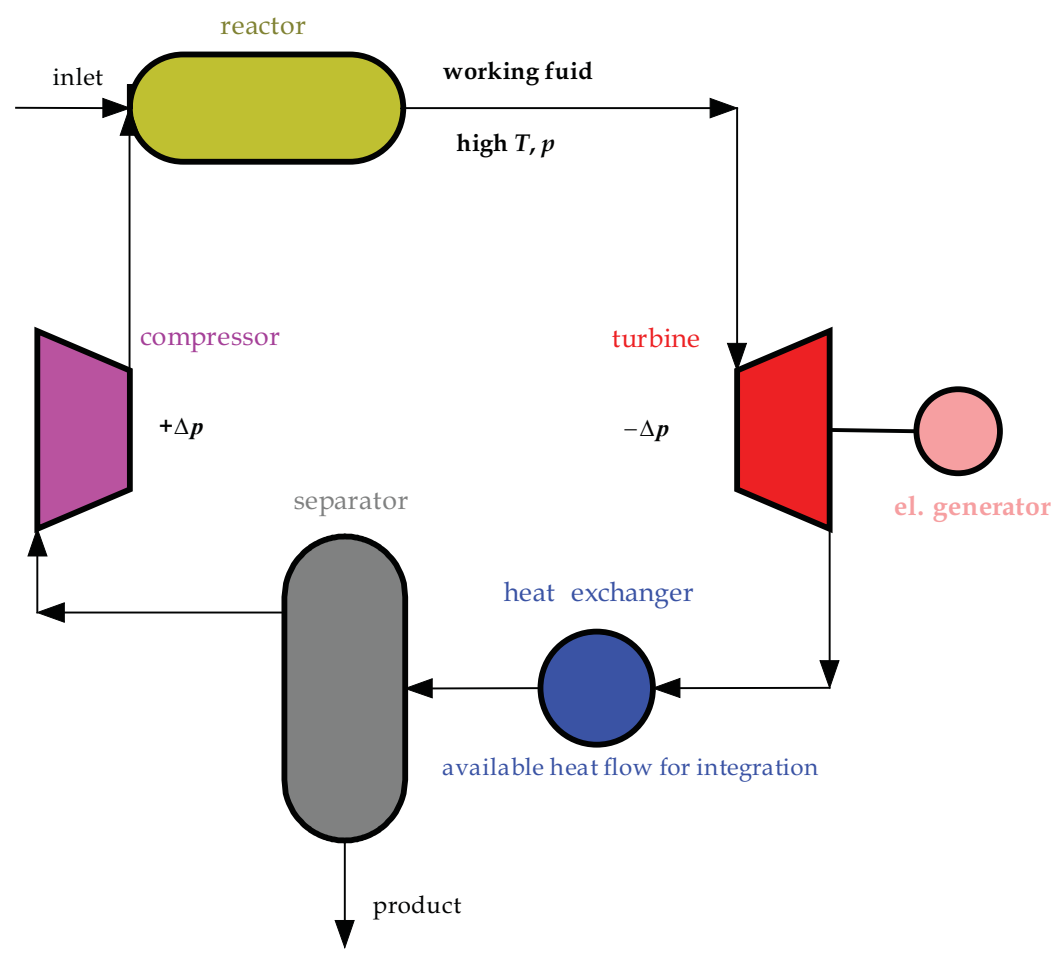

Fig. 2. Open gas turbine system

\section{Open gas turbine system}

The gas turbine has rendered increasing service within the petrochemical industry. Opencycle gas turbine power plants are widely applied throughout industry. A conventional power plant uses fuel energy to produce work.

Usually, a gas turbine operates by internal combustion. Air and fuel pass through a compressor into a combustion chamber. The combustion products are then expanded in a turbine, which drives an electric generator.

Many chemicals are produced under high pressure and at high temperatures. The reactor acts as the combustion chamber of the gas turbine plant. Then, separation at lower pressure and temperature follows and this pressure change can be used to drive a turbine, coupled to an electricity generator.

Our main purpose is to use existing gases from within the chemical processes to drive the turbine by using an open gas turbine system. An open gas turbine system includes the following process units, in order (Fig. 3):

- $\quad$ reactor $(\mathrm{R})$

- gas turbine $(\mathrm{T})$ with electric generator

- heat exchanger $(\mathrm{H})$

- $\quad$ separator (S), where the liquid product separates off and

- compressor (C). 
The high operating pressure at the reactor's outlet can be exploited to produce electricity using an open gas turbine. The open gas turbine is a basic gas turbine unit. This turbine uses processed gas as a working fluid. The working fluid comes from the reactor and circulates through the following units (Fig. 3):

- $\quad$ gas turbine $(\mathrm{T})$

- heat exchanger $(\mathrm{H})$

- $\quad$ separator $(\mathrm{S})$, where the liquid product separates off and

- compressor $(\mathrm{C})$.

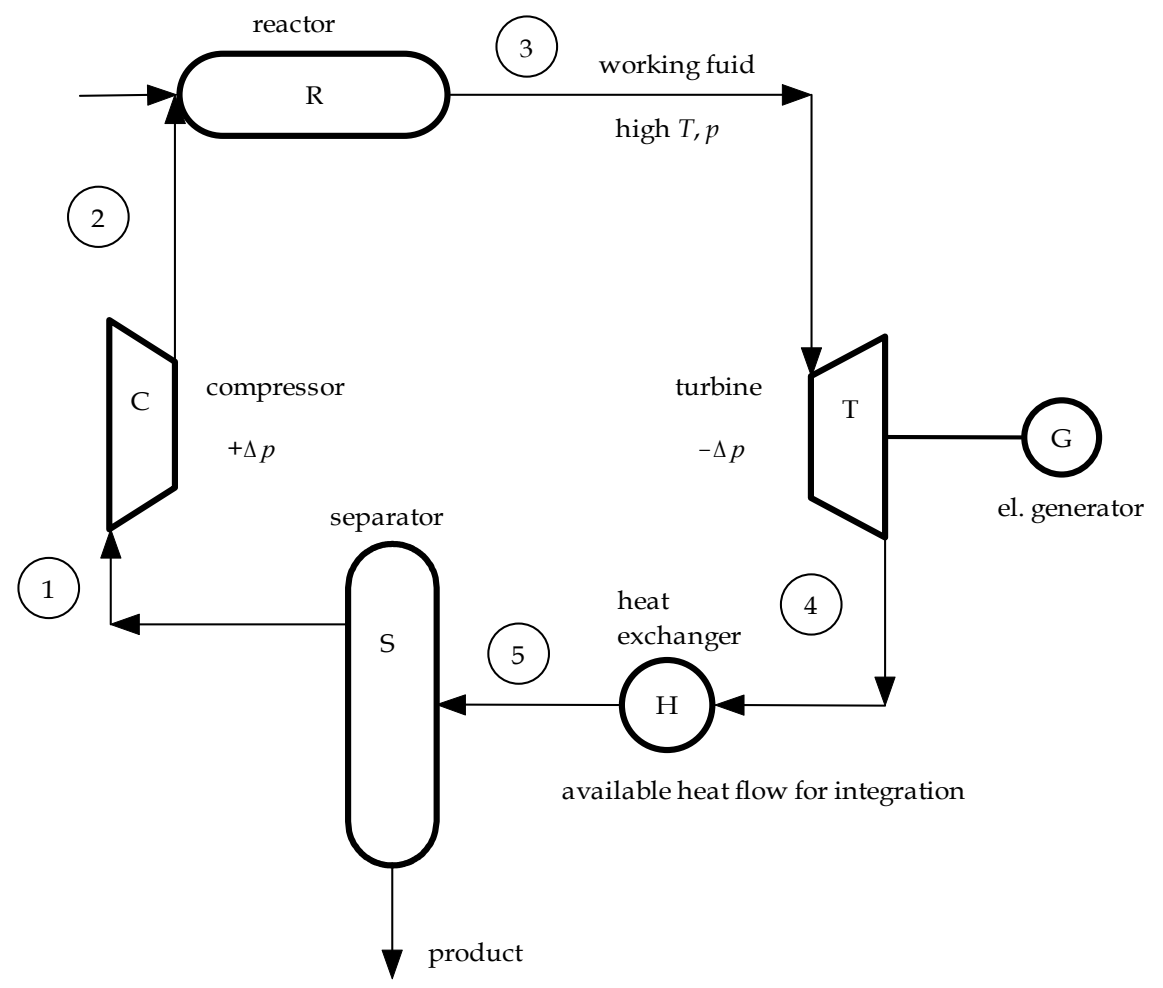

Fig. 3. Open circuit gas turbine system

The power cycle of the open gas turbine system is described as the "Brayton cycle". The working fluid undergoes the following process steps, as shown in a simplified $\mathrm{T} / \mathrm{s}$ (temperature/mass entropy) diagram (Fig. 4):

- 1-2 adiabatic compression

- 2-3 reaction

- 3-4 adiabatic expansion of reaction outlet stream in a turbine

- 4-5 cooling or/and available heat flow for heat integration

- 5 separation.

The individual processes' units in the open gas turbine system have their own importance, and will be presented individually. 


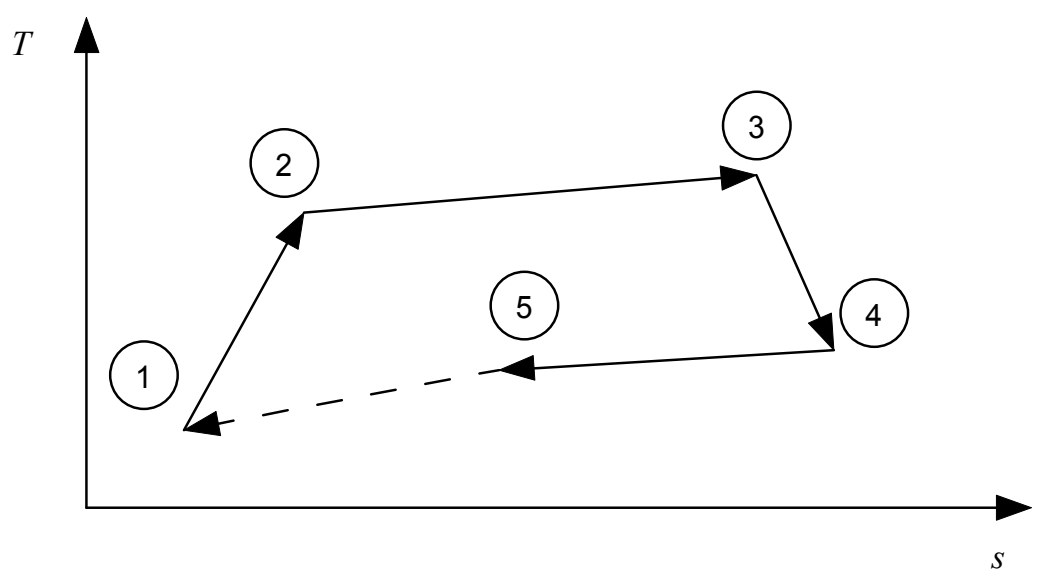

Fig. 4. The simplified temperature/mass entropy $(T / s)$ diagram

\subsection{Reactor (R)}

The reactor processing unit for the production of various products, in our case concentrating in particular, on those that operate and produce under high pressures. The high pressure reactor model is presented with all components $\mathrm{s}(\mathrm{s}=1, \ldots \mathrm{S})$, which react at different reactions $\mathrm{r}(\mathrm{r}=1, \ldots \mathrm{R})$. The amount flow rate from the reactor affects the power of the turbine. The thermodynamic and kinetic properties of the chemical reactions $(r=1, \ldots, R)$ provide a good prediction about flow rate and the compositions of the raw material, its conversion to a product, and parameter conditions. The amount flow rate $(F)$ for any component $(s=1, \ldots, S)$ depends on the equilibrium constant $\left(K_{\mathrm{e}}\right)$. For the hypothetical reversible chemical reaction:

$$
v_{\mathrm{A}} \mathrm{A}+v_{\mathrm{B}} \mathrm{B} \leftrightarrows v_{\mathrm{C}} \mathrm{C}+v_{\mathrm{D}} \mathrm{D}
$$

the equilibrium constant is defined as:

$$
K_{e}=\frac{c_{C}^{v_{C}} \cdot c_{D}^{v_{D}}}{c_{A}{ }^{v_{A}} \cdot c_{B}^{v_{B}}}
$$

where $v_{\mathrm{s}}$ are stoichiometric coefficients, and $c_{\mathrm{s}}$ concentrations of components s.

The equilibrium constant determines the extent of a chemical reaction at equilibrium. It can be calculated if the equilibrium concentration of each reactant and product in a reaction at equilibrium is known.

The conversion rate of reaction $\mathrm{r}\left(\omega_{\mathrm{r}}\right)$ can be calculated from the differential change of the reaction extent $\left(\mathrm{d} \xi_{\mathrm{r}}\right)$, after time $t$ :

$$
\omega_{\mathrm{r}}=\mathrm{d} \xi_{\mathrm{r}} / \mathrm{d} t \quad \mathrm{r}=1, \ldots, \mathrm{R}
$$

Any differential change in the reaction extent $\left(\mathrm{d} \xi_{\mathrm{r}}\right)$ can be calculated from the differential change in its amount $\left(\mathrm{d} n_{\mathrm{s}}\right)$, and its stoichiometric coefficient $(v)$ :

$$
\mathrm{d} \xi_{\mathrm{r}}=\mathrm{d} n_{\mathrm{s}} / v_{\mathrm{s}, \mathrm{r}} \quad \mathrm{s}=1, \ldots, \mathrm{S} \quad \mathrm{r}=1, \ldots, \mathrm{R}
$$


The extent of a reaction characterizes how far the advancement of the reaction has taken place. Equation 2 has to integrate from an initial $\xi_{\mathrm{r}}=0$ and $n_{\mathrm{s}}=n_{\mathrm{s}, \text { in }}$ to outlet $\xi_{\mathrm{r}}$ and $n_{\mathrm{s}, \text { out }}$ :

$$
\int_{n_{\mathrm{s}, \mathrm{in}}}^{n_{\mathrm{s} \text {, ut }}} \mathrm{d} n_{\mathrm{s}}=v_{\mathrm{s}, \mathrm{r}} \int_{0}^{\xi_{r}} \mathrm{~d} \xi_{r} \quad \mathrm{~s}=1, \ldots, \mathrm{S} \quad \mathrm{r}=1, \ldots, \mathrm{R}
$$

and the outlet amount for component $\mathrm{s}$ for reaction $\mathrm{r}$ is:

$$
F_{\mathrm{s}, \text { out }}=n_{\mathrm{s}, \text { in }}+\sum_{\mathrm{r}} v_{\mathrm{s}, \mathrm{r}} \xi_{\mathrm{r}} \quad \mathrm{s}=1, \ldots, \mathrm{S} \mathrm{r}=1, \ldots, \mathrm{R}
$$

The amount flow rate $F$ is defined as:

$$
F_{\mathrm{s}}=\mathrm{d} n_{\mathrm{s}} / \mathrm{d} t \quad \mathrm{~s}=1, \ldots, \mathrm{S}
$$

and outlet amount flow rate for component $\mathrm{s}$ is:

$$
F_{\mathrm{s}, \text { out }}=F_{\mathrm{s}, \text { in }}+\sum_{\mathrm{r}} v_{\mathrm{s}, \mathrm{r}} \omega_{\mathrm{r}} \quad \mathrm{s}=1, \ldots, \mathrm{S} \mathrm{r}=1, \ldots, \mathrm{R}
$$

The total outlet amount flow rate $(F)$ is:

$$
F=\sum_{s} F_{\mathrm{s}, \text { out }} \quad \mathrm{S}=1, \ldots, \mathrm{S}
$$

The equilibrium constant $\left(K_{\mathrm{r}}\right)$ of reaction $\mathrm{r}$ (Smith \& Ness, 1987) can be calculated by the minimization of Gibbs (free) energy $(\Delta G)$ :

$$
K_{\mathrm{r}}=\mathrm{e}^{\left(-\Delta_{\mathrm{Gr}} / R T\right)} \quad \mathrm{r}=1, \ldots, \mathrm{R}
$$

High reactant flow rate favours reactions with higher conversion and optimization of raw material composition and can increase production.

The changing amount flow rate for reactant $(\Delta F)$ affects the heat flow rate of the outlet reaction stream $(\Phi)$, which can enlarge electricity cogeneration and heat integration during a process (Fig. 5). This simultaneous approach can optimize the trade-off between heat and electricity cogenerations. Cogeneration is constrained by the lowest possible outlet temperature of the gas turbine. Cogeneration chooses the lowest temperature limit, thus cogeneration is usually more profitable than heat integration.

\subsection{Turbine ( $\mathrm{T})$}

The power of the gas turbine depends on the primary variables: inlet temperature, compressed pressure ratio and mass flow. The inlet temperature is restricted by the metallurgical limit of the turbine's blades to about $800^{\circ} \mathrm{C}$.

The medium pressure of the designed turbine can be varied. Its power $\left(P_{\text {tur }}\right)$ is a function of the outlet temperature $\left(T_{\text {tur, out }}\right)$, molar heat capacity $\left(C_{\mathrm{m}}\right)$ and the amount flow rate $(F$; see Equation 9):

$$
P_{\text {tur }}=C_{\mathrm{m}} \cdot\left(T_{\text {tur, in }}-T_{\text {tur, out }}\right) \cdot F
$$

Gas turbine power $\left(P_{\text {tur }}\right)$ is a function of:

- $\quad$ outlet temperature $\left(T_{\text {tur,out }}\right)$ 


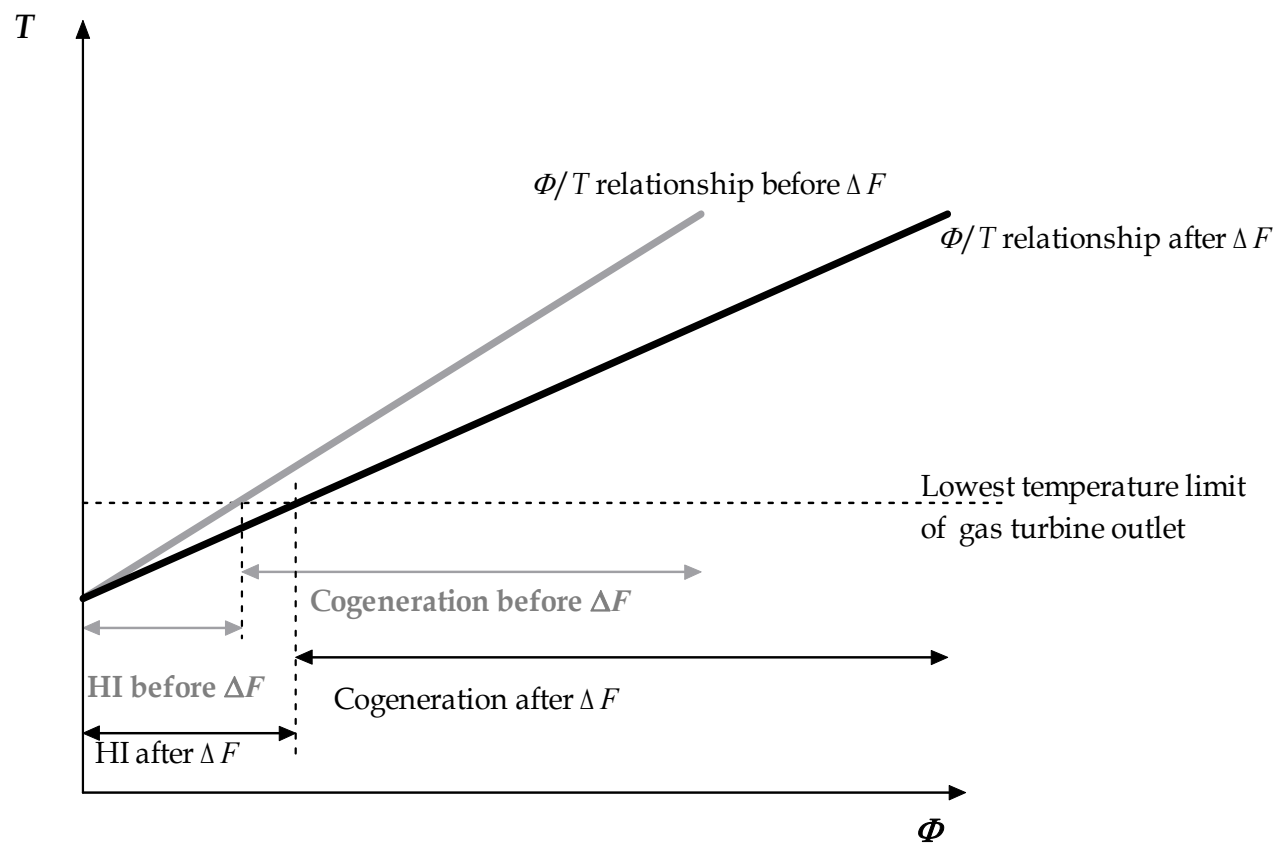

Fig. 5. The simplified temperature/heat flow rate $(T / \Phi)$ diagram before and after changing the flow rate $(\Delta F)$ of the raw material: performing heat integration $(\mathrm{HI})$, and cogeneration before and after $\Delta F$.

- molar heat capacity $\left(C_{\mathrm{m}}\right)$

- amount flow rate $(F)$

The inlet temperature $\left(T_{\text {tur,in }}\right)$ is kept constant. The thermodynamic efficiency of the medium pressure turbine $\left(\eta_{\text {tur }}\right)$ and the mechanical efficiency of the generator $\left(\eta_{\text {gen }}\right)$ is supposed to be $85 \%$ for each.

The annual depreciation of the medium pressure turbine $\left(C_{d, t u r}\right.$ in EUR/a) is a function of the power $\left(P_{\text {tur }}\right.$; Biegler et al., 1997):

$$
C_{\mathrm{d}, \text { tur }}=\left(22946+13.5 \cdot P_{\text {tur }}\right) \cdot 4
$$

The published cost equations for the equipment are not usually adjusted to the real, higher industrial costs, therefore, the costs are multiplied by a factor (4), determined by experience.

\subsection{Heat exchanger $(\mathrm{H})$}

The residual heat in the heat exchanger $(\mathrm{H})$ can usefully be applied to the heat integration. The heat flow $(\Phi)$ can be calculated with known inlet $\left(T^{\mathrm{in}} \mathrm{H}\right)$ and outlet temperatures $\left(\mathrm{Tout}_{\mathrm{H}}\right)$, by using equation 11 :

$$
\left(\operatorname{Tin}_{\mathrm{H}}-\mathrm{Tout}_{\mathrm{H}}\right) \cdot C F_{\mathrm{H}}=\Phi_{\mathrm{H}}
$$

where $C F_{\mathrm{H}}$ is the heat capacity flow rate of the stream in heat exchanger. 


\subsection{Separator (S)}

The separator has the task of separating liquid from the vapour phase. The product is in liquid phase. Vapour flow is compressed in the compressor (C). The balanced amounts of the separation for all the components $(\mathrm{s}=1 \ldots \mathrm{S})$ are:

$$
\begin{gathered}
F^{\text {in }}=F^{\text {out }, \mathrm{v}}+F^{\text {out }, 1} \\
F^{\text {in }} \cdot x^{\text {in }}=F^{\text {out }, \mathrm{v}} \cdot x^{\text {out }, \mathrm{v}}+F^{\text {out }, 1} \cdot x^{\text {out }, 1} \quad s=1, \ldots, \mathrm{S} \\
\sum_{\mathrm{s}}^{\mathrm{S}} x_{\mathrm{s}}^{\mathrm{out}, \mathrm{v}}=1 \\
\sum_{\mathrm{s}}^{\mathrm{S}} x^{\text {out }, 1}{ }_{\mathrm{s}}=1 \\
K_{\mathrm{s}}=\mathrm{d}_{\mathrm{s}}+\mathrm{c}_{\mathrm{s}} \cdot T^{\text {out }}+\mathrm{b}_{\mathrm{s}} \cdot\left(T^{\text {out }}\right)^{2} \quad \mathrm{~s}=1, \ldots, \mathrm{S}
\end{gathered}
$$

where $d_{s}, c_{s}$ and $b_{s}$ are equilibrium constants during separation

$$
x^{\text {out }, \mathrm{v}_{\mathrm{s}}}=K_{\mathrm{s}} \cdot x^{\text {out }, \mathrm{l}_{\mathrm{s}}} \mathrm{s}=1, \ldots, \mathrm{S}
$$

The inlet amount flow rate for separation $(F$ in $)$ is the sum of the outlet amounts flow rates of the vapour (Fout,v) and liquid phases (Fout,l ; see Equation 12). Equation 13 includes the amount flow fractions. $x$ is the amount fraction in vapour (v) or liquid phase (l). The equilibrium constant $(K)$ of the $\mathrm{s}^{\text {th }}$ component during separation is a function of temperature (see Equation 16).

\subsection{Compressor (C)}

Vapour flow from the separator is compressed within the compressor (C). The temperatures at the outlets of the compressor ( out $_{c}$; depend on the inlet temperatures $\left(\mathrm{Tin}_{\mathrm{c}}\right)$, and can be calculated by the equation:

$$
\mathrm{T}_{\mathrm{c}}^{\text {out }}=\mathrm{a}_{\mathrm{c}}+\mathrm{b}_{\mathrm{c}} \cdot \mathrm{T}_{\mathrm{c}}^{\mathrm{in}}
$$

where $a_{c}$ and $b_{c}$ are the temperature constants for polytropic compression.

Once we know, the whole model of the open gas turbine system can be optimized, using different methods.

\section{Case study}

The suggested open gas turbine system was tested in an existing complex, low-pressure Lurgi methanol plant producing crude methanol by using nonlinear programming (NLP; Biegler et al., 1997). The parameters in the model of an open gas turbine were simultaneously optimized using the GAMS/MINOS (Brooke at al.; 1992). This NLP can be solved using a large-scale reduced gradient method (e. g. MINOS). The model is nonconvex, it does not guarantee a global optimization solution but it quickly gives good results for non-trivial, complex processes. The NLP model contains variables of all those process' 
parameters: molar heat capacities, material flow rates, heat flow rates, and temperatures, which are limited by real constraints.

\subsection{Results}

The simultaneous NLP of heat and power integration, and the optimization selected for electricity generation using a gas turbine pressure drop from 49.7 bar to 35 bar with an outlet temperature of $T_{\text {tur, out }}=110{ }^{\circ} \mathrm{C}$ (Fig. 6). This structure enables the generation of 12.7 MW of electricity. The steam exchanger (HEST) needs 16.5 MW of heat flow rate. The integrated process streams in HEPR, exchange 3.6 MW of heat flow rate. The power of the first and the second compressors are 2.0 MW and $2.8 \mathrm{MW}$, respectively. The HEW1 exchanges 2.0 MW. Within the heat exchangers, HEW and HEA 7.1 MW and 4.7 MW of heat flow rate are exchanged with the existing areas, respectively, when cooling. The additional annual of methanol production is $0.75 \mathrm{~mol} / \mathrm{s}$, purge gas outlet flow rate is decreased from $210 \mathrm{~mol} / \mathrm{s}$ to $190 \mathrm{~mol} / \mathrm{s}$.

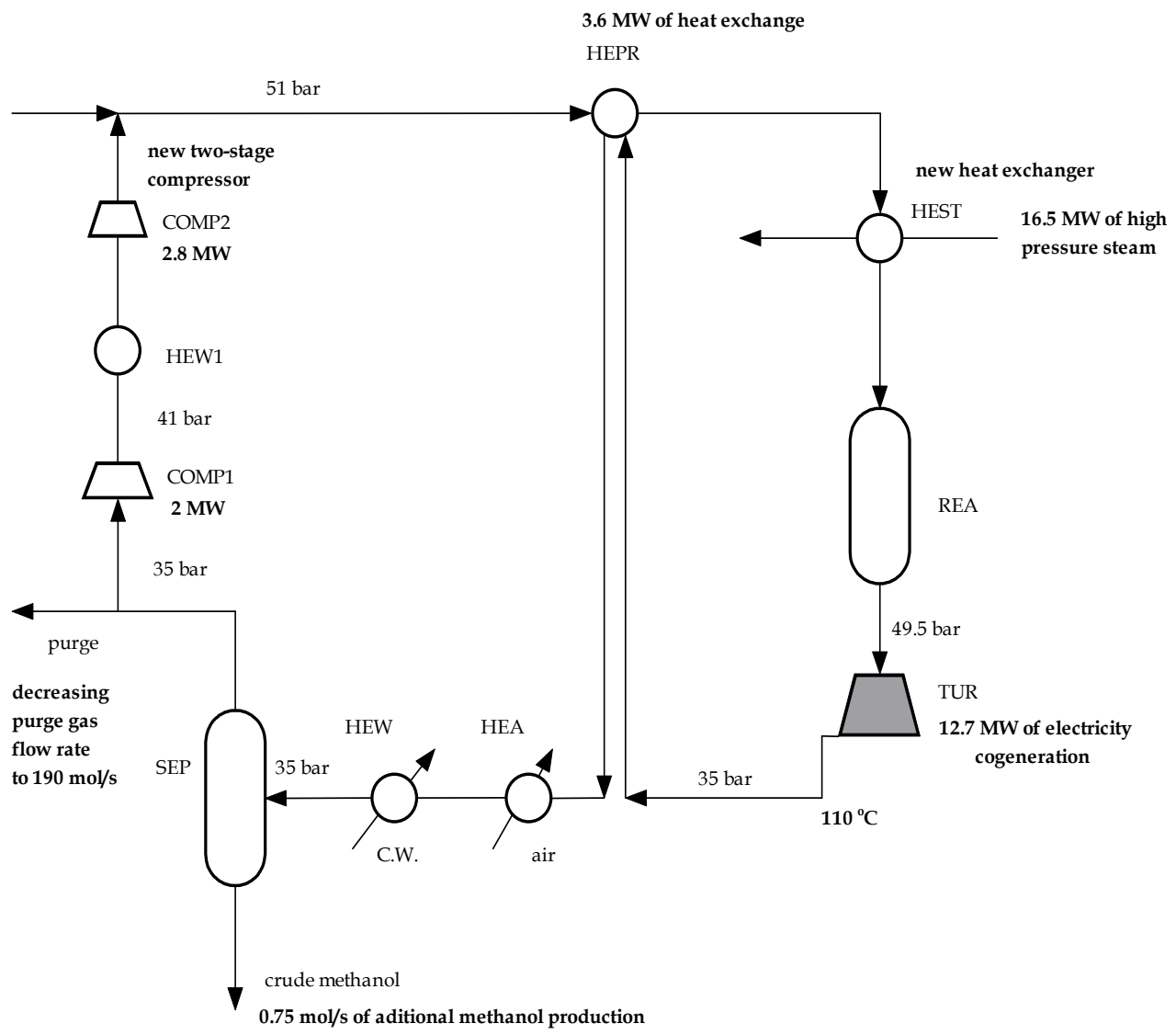

Fig. 6. Optimised flow sheet for crude methanol production, using a open gas turbine system 
The additional annual depreciation of the gas turbine, new heat exchangers (HEST, HEW1, having areas of $527 \mathrm{~m}^{2}$ and $324 \mathrm{~m}^{2}$ ), and the new two-stage compressor, is $2040 \mathrm{kEUR} / \mathrm{a}$ (Table 1). The cost of the high pressure steam used in HEST is $1750 \mathrm{kEUR} / \mathrm{a}$. In the depreciation account for retrofit, we included additional costs to the new units only: 30 $\mathrm{kEUR} / \mathrm{a}$ for the instrumentation cost (which is estimated to be $15 \%$ of the additional direct plant cost), $10 \mathrm{kEUR} / \mathrm{a}$ for the contingency (estimated at $5 \%$ of the additional direct plant cost), $4 \mathrm{kEUR} / \mathrm{a}$ for the maintenance cost (estimated as $2 \%$ of the additional direct plant cost), and $15 \mathrm{kEUR/a}$ for the turbine down time (estimated as $5 \%$ of the additional plant direct cost). The additional annual income of the electricity produced is $5530 \mathrm{kEUR} / \mathrm{a}$. The additional annual income of the methanol produced is $79 \mathrm{kEUR} / \mathrm{a}$. The additional profit from process and power integration is estimated to be $1760 \mathrm{kEUR} / \mathrm{a}$ for the modified process.

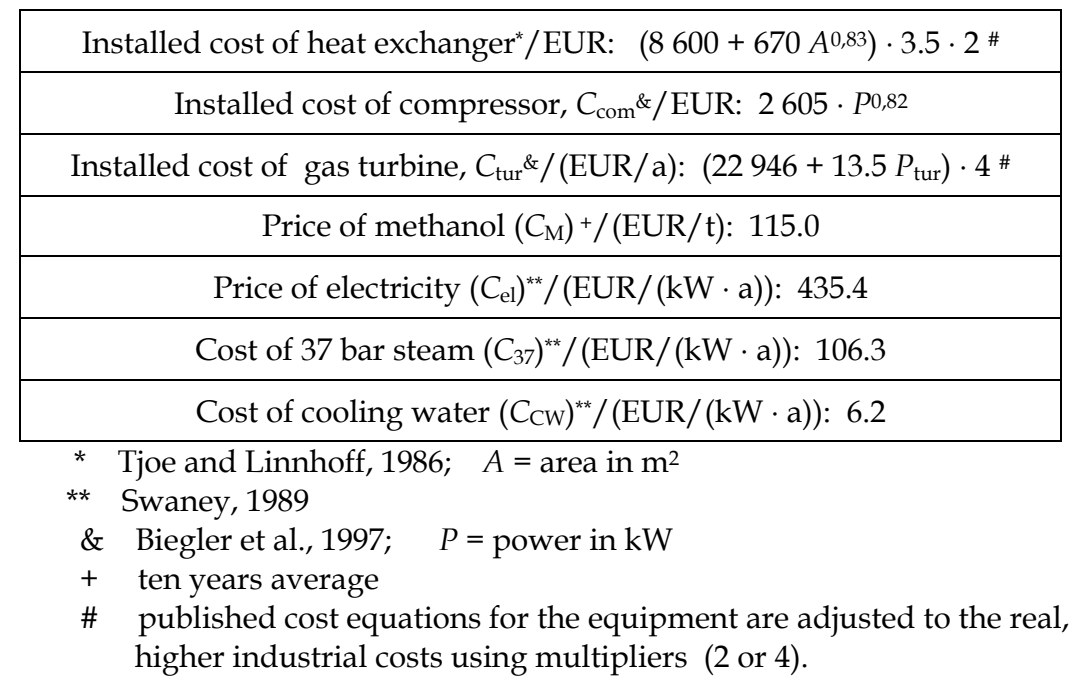

Table 1. Cost items for example process

\section{Conclusion}

The inclusion of open gas turbine can increase the operating efficiency of the process. The gas turbine with its pressure and temperature drop can be included in the process cycle. The working fluid comes from the reactor and circulates through the process units: gas turbine, heat exchanger, separator (where the liquid product separates), and the compressor.

\section{References}

Biegler, L. T.; Grossmann, I. E. \& Westerberg, A. W. (1997). Systematic methods of chemical process design, Prentice Hall, Upper Saddle River, New Jersey, 1-408.

Brooke, A.; Kendrick D. \& Meeraus, A. (1992). GAMS: A User's Guide, Palo Alto, Scientific Press. 
Smith, J.M. \& Van Ness, H.C. (1987). Introduction to chemical engineering thermodynamics, McGraw-Hill, New York, 496-518.

Swaney, R. (1989). Thermal integration of processes with heat engines and heat pumps, AIChE Journal 35/6, pp. 1010.

Tjoe, T. N. \& Linnhoff, B. (1986). Using pinch tehnology for process retrofit. Chem. Engng 28 $47-60$. 


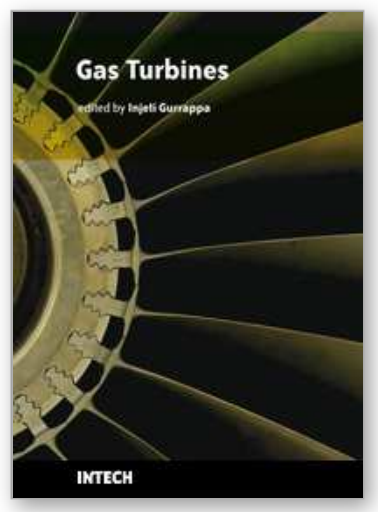

\author{
Gas Turbines \\ Edited by Gurrappa Injeti
}

ISBN 978-953-307-146-6

Hard cover, 364 pages

Publisher Sciyo

Published online 27, September, 2010

Published in print edition September, 2010

This book is intended to provide valuable information for the analysis and design of various gas turbine engines for different applications. The target audience for this book is design, maintenance, materials, aerospace and mechanical engineers. The design and maintenance engineers in the gas turbine and aircraft industry will benefit immensely from the integration and system discussions in the book. The chapters are of high relevance and interest to manufacturers, researchers and academicians as well.

\title{
How to reference
}

In order to correctly reference this scholarly work, feel free to copy and paste the following:

Anita Kovac Kralj (2010). Electricity Cogeneration Using Open Gas Turbine, Gas Turbines, Gurrappa Injeti (Ed.), ISBN: 978-953-307-146-6, InTech, Available from: http://www.intechopen.com/books/gasturbines/electricity-cogeneration-using-open-gas-turbine

\section{INTECH}

open science | open minds

\author{
InTech Europe \\ University Campus STeP Ri \\ Slavka Krautzeka 83/A \\ 51000 Rijeka, Croatia \\ Phone: +385 (51) 770447 \\ Fax: +385 (51) 686166 \\ www.intechopen.com
}

\author{
InTech China \\ Unit 405, Office Block, Hotel Equatorial Shanghai \\ No.65, Yan An Road (West), Shanghai, 200040, China \\ 中国上海市延安西路65号上海国际贵都大饭店办公楼 405 单元 \\ Phone: +86-21-62489820 \\ Fax: +86-21-62489821
}


(C) 2010 The Author(s). Licensee IntechOpen. This chapter is distributed under the terms of the Creative Commons Attribution-NonCommercialShareAlike-3.0 License, which permits use, distribution and reproduction for non-commercial purposes, provided the original is properly cited and derivative works building on this content are distributed under the same license. 